\title{
Looking Back on 20 Years: The Michigan Family Review
}

\author{
Heather Dillaway \\ Wayne State University
}

* Please address correspondence to Heather Dillaway, PhD, Professor of Sociology and General Editor of Michigan Family Review, 2237 FAB, 656 W. Kirby, Detroit, MI 48202. Email: dillaway@wayne.edu.

\section{Introduction}

As the fourth General Editor of Michigan Family Review (MFR), I am happy to present the $20^{\text {th }}$ anniversary volume of this peer-reviewed, interdisciplinary journal. MFR was founded in 1995 by the Michigan Council on Family Relations and by Founding Editor, Libby Balter Blume (Professor of Psychology, University of Detroit Mercy). While the Michigan Council on Family Relations no longer exists, this journal lives on and fulfills its legacy. MFR has provided a local and regional forum for professionals and scholars interested in understanding and strengthening families. There have been many special issue editors throughout the years, adding to the interdisciplinary and diverse nature of the journal's volumes and its focus on both scholarly inquiry and professional application. In most years, MFR has represented an annual peer-reviewed volume highlighting a single theme or focus on families. Themes have been varied across volumes, including family-related topics such as death and dying, educational reform, health care, feminism, unemployment, welfare reform, time, religion, legal matters, and intergenerational relationships, to name a few. Contributors have also been a varied bunch as editors have tried to make sure that researchers, teachers, and practitioners in a variety of fields and disciplines have been invited to submit manuscripts to MFR. Some accepted articles have been based in empirical research and others have represented policy review, literature reviews, theoretical work, and scholarly reports on practice.

Libby Balter Blume shepherded MFR for its first 10 years and its first 10 volumes (11 issues), and took the journal from print to online in 2003. Michigan Publishing (a division of the University of Michigan Library) has hosted MFR since the transition to online publication, and has facilitated the later work of the Founding Editor, two subsequent General Editors (Martin A. Covey (2006-2009) and Brad van Eeden-Moorefield (2009-2012)), and myself, to insure that our scholarly content is readily available to readers. It has been a pleasure to work with teams at Michigan Publishing to produce this journal. Individuals such as 
Rebecca Welzenbach, Kelly Witchen, Amanda Karby, and many others at Michigan Publishing have facilitated the success of MFR in recent years, but we thank all of the team members at Michigan Publishing for their commitment to MFR over the past 13-14 years.

Thinking comparatively, MFR is a small online journal. Nonetheless, MFR has regular readers. With the help of Michigan Publishing, we have been able to track Google Analytics on the readership of our published articles over the past few years, and we see quite a bit of traffic to our site and also to particular articles. We have monitored how well-read certain MFR articles are on our journal's site, tracking the top 10 most well-read pieces each month. While there is some variation among the top 10 each month, some articles consistently stay on the list. As a result, we decided to engage in this $20^{\text {th }}$ anniversary volume so that we can honor some of the authors who have contributed these well-read articles in MFR. Specifically we invited selected authors of well-read pieces to write an "update" to their original MFR articles. In this volume, we include both a new and old piece from some of our most popular authors, not only to showcase their original work but also to give them a chance to respond back to themselves and expand upon their ideas. As readers can view for themselves, the authors included in this volume are a varied bunch and they represent many Michigan universities and colleges as well as disciplinary fields.

In volume 20, we include five authors' updates as well as links to their original MFR articles. Our first author, Thomas Blume, revisits a 1996 article on the social understandings of violence. In his update, Thomas Blume reviews changing patterns of violence across the last 20 years, theoretical explanations for violence, and the ways in which types of violence, prevention, and treatment have changed. Second, Moushumi Roy Choudhury and Clifford Broman revisit another 1996 article on the impact of unemployment on families, focusing more specifically in their new article on the stressors that families endure and navigate in the face of job loss and the implications for family dynamics and well-being. Rosemary Ziemba, our third contributor, reviews her 2002 article about elderly caregiving dilemmas and the implications for family caregivers and family health. Ziemba uses her update piece to explore the differences in her own perspective between 2002 and 2016, as she reaches a new personal life stage and her own new caregiving quandaries. Elizabeth Pare`, our fourth author, revisits a 2005 article on stay-at-home versus working motherhood, and focuses her update on how an era of decreased economic security makes it even more unrealistic for mothers to reach for ideals of "good" or "intensive" motherhood. Finally, our fifth update is provided by Gary Bischof, Codie Stone, Mariam M. Mustafa, and Theodore J. Wampuszyc, and this team of co-authors respond to a MFR article from 2011. Bischof and his co-authors review the important ways in which our language and understanding of transgender individuals and their intimate relationships have changed, even within the past decade. Together, these pieces showcase the incredible diversity of articles published in this interdisciplinary journal.

Evidenced by the work emphasized in these five selections, MFR provides an important interdisciplinary space for researchers and practitioners interested in understanding and bolstering families, both in Michigan and beyond. Michigan 
families represent all families. Likewise, MFR publishes peer-reviewed articles that can speak to national and international issues surrounding contemporary families. Unemployment, violence, motherhood, elderly caregiving, and transgender relationships are the broad subjects of this anniversary volume, and the authors of this volume have original MFR articles that have been read well by authors all over the United States and abroad. We at MFR hope to continue publishing scholarly work that resonates with our readership and facilitates this broader and more interdisciplinary understanding of families.

Thanks to all for supporting the first 20 years of MFR, and we look forward to producing future volumes for our readers. Readers should look for the publication of volume 21 by late Fall 2017. 